\title{
The Surgical Care Improvement Project (2004), and Finally Some Progress
}

\author{
Hiram C. Polk Jr., MD and Stephen O'Brien, MB BCh BAO
}

The Hiram C. Polk Jr., MD Department of Surgery, University of Louisville School of Medicine, Louisville, KY

In 2004-2005, there was a cooperative effort for a number of surgical organizations to work jointly for quality improvement in many aspects of surgery, which resulted in the creation of the Surgical Care Improvement Project (SCIP). Among the simplest measures was the decision to routinely administer systemic antibiotics for clean-contaminated operations and to others at risk within an hour before the operation; to repeat the dose of antibiotics if the operation was prolonged; and, finally (and most importantly), to discontinue antibiotics within a day or two postoperatively. That quickly became the norm. This is something the senior author (Polk) had worked on since 1969 and came to pass, led primarily by the American Academy of Orthopedic Surgery and the American College and Obstetrics and Gynecology. Other aspects of the SCIP have been less clear. The goal was to improve the quality metrics by $25 \%$ in a 10 -year period. One can take any part of surgery and see whether or not those improved factors were achieved. Millions of dollars were spent, nurses with clipboards were everywhere, and awareness was achieved; improvement-perhaps not. A key and interesting point is the overt conflicts of interest involved with this on the part of people who are frequently consultants, even stockholders, in the companies that benefit from new recommendations or stronger enforcement. That is entirely another story. The article by Lee et al. has a very simple focal point, i.e. on lessening the routine amount of narcotics that are sent home with patients after modest, often outpatient, oncologic surgery.

(C) Society of Surgical Oncology 2018

First Received: 1 August 2018;

Published Online: 30 October 2018

H. C. Polk Jr., MD

e-mail: hcpolk01@louisville.edu
One only has to look at the senior author's experience as Kentucky's Commissioner of Public Health for only a little past a year in Frankfort, KY, to see what a tremendous problem the use of illicit drugs is, notably oxycodone, progressing on to fentanyl, and their substitute medications. Interestingly, it was found that the most prevalent age of people dying of opioid overdoses in Kentucky in 2014 was the generation aged $45-54$ years. Put away as something not initially understood, our focus continued on the young people experimenting with drugs and dying in their 20s. The senior author also had the chance to sit in on the proceedings of the Kentucky Board of Medical Licensure for a time and realized what a difficult scenario it was to do their best through the licensing process, while at the same time permitting overtly suspicious practitioners to retain their licenses until proven to the contrary. Kentucky was the first Board of Medical Licensure in America to withdraw the license of a doctor for administering a US FDA-approved drug in large amounts to patients over a long period of time. The "pill mill atmosphere" was common and is the subject of a remarkable book by Sam Quinones called Dreamland, ${ }^{1}$ focusing on Southeastern Ohio, Southwestern Pennsylvania, West Virginia, and Eastern Kentucky. In 2016, it finally made sense that those deaths of 45-year-olds might have been due to people who began to take medication for pain that was unrelenting, notably due to back pain related to heavy employment such as a truck manufacturing plant in Louisville, or in the deep coal mines of Eastern Kentucky. Only then was it possible to begin to read dozens of intelligent papers that point out that many surgeons unknowingly have prescribed far more oxycodone-type drugs than were reasonably needed for a postoperative period. It became the norm rather than the exception to avoid weekend calls for renewal of prescriptions. Much was learned from our orthopedic group at the time that would not allow any of their physicians to issue a prescription for pain medication after 3:00 pm on Friday 
and before 10:00 am on Monday. It was a step forward. The theme of the article of the group from Michigan, which has done so much for the SCIP in a broad sense, is that some fairly straightforward elective operations can be done with a lessening of prescription narcotics. ${ }^{2}$ It is obviously true, and much of surgical specialty practice has become alert to this problem. Most of us are aware of, and sharply reducing, not only the number but also the strength and duration of postoperative pain medication. This is especially true in ambulatory surgery, even for procedures that are not minor, such as cholecystectomy or knee replacement. As was always true under the directorship of Campbell, and his pupils who are the authors of the paper, was the chance to use the Michigan consortium for quality (substantially supported by Anthem, which was then nearly a single insurer in Michigan for automotive-related industries). Unlike many of the other surgical care improvement programs, this one clearly shows improvement in a short period of time.

The only Achilles heel of this paper is that, as pointed out by the authors, $99 \%$ of prescriptions were written by residents, and they were under sharply constrained orders not to write for more than a specified number of narcotics and/or potentially addictive drugs. It is not surprising that in a top-quality surgical training program, such as the one at the University of Michigan, those directions would be followed specifically. It will be a harder task to get that accomplished in a large group of private physicians who work out of ambulatory care centers and/or hospitals in the present era. However, this is a clear example of improvement in an area that is focused, intelligent, and deliverable. It would be extremely useful if a similar path could be demonstrated within a large private hospital not influenced by directions from the Program Director and/or Chair of Surgery, as was done in this highly academic atmosphere.

Cancer is often used as one of the exclusions whereby any physician has the right to take exception to the rules and order larger amounts of pain medicine. Sharing with the readership from his own personal experiences, Dr. Polk said: "I liked to make myself an example of that when I had a knee replacement 6 years ago. I was administered a large amount of oxycodone prescription as I walked out the door $(n=50)$; however, I have only used 15 of them. This is an easy place to make progress. The later adult and/or middle-aged person who becomes hooked on drugs is a doctor-related problem. Drug addiction is a process that has a $<25 \%$ cure rate. Almost nobody wants to admit that, but I assure you that my experience as Commissioner of Public
Health within the epicenter of the 'pill mill area' convinces me that it is true." The value of the paper is to ask all surgeons to look at this element of care and see how much they can appropriately limit narcotic prescriptions for postoperative patients. It is only a small part of the war against drugs, but it is a part that we can, as has been the behavior of surgeons forever, take leadership and be the example of control. We can only await the confirmation of these same observations in the private hospital arena, where the habits of doctors and surgeons are notoriously hard to change. If we do so, it will have to be done in a clear and firm way because we think that many doctors still do not accept their capacity to produce addiction when they are writing for short-term, postoperative pain relief. The issue is not the amount of pain medication as much as the duration. We think this concept is catching on quickly, and it seems that more and more groups are writing and talking about the success of programs such as this. It needs to get beyond something other than orders to the junior resident and be accepted by surgeons in healthcare systems around the country.

Taken as a whole, we fear the SCIP will be judged to have failed, i.e. $25 \%$ improvement in outcomes such as wound infection, postoperative cardiac events, etc. Interestingly, while the frequent use of postoperative anticoagulants to prevent venous thromboembolism has had little impact on the development of serious pulmonary embolism, it has had a massive financial benefit for the drug companies. It is difficult to make progress, particularly in a cumbersome divided healthcare system such as ours. This is one of the few times that make you wish for the rigidity and clarity of purpose of the National Health Service in the UK. Indeed, their National Institute for Health and Care Excellence (NICE) and Scottish Intercollegiate Guidelines Network (SIGN) programs convene regularly to assess not only results but also to reconsider earlier recommendations that have proved to be either correct or incorrect. The SCIP has not been systematically reassessed since its creation in 2004.

\section{REFERENCES}

1. Quinones, S. Dreamland: the true tale of America's opiate epidemic. New York: Bloomsbury Press; 2016.

2. Lee JS, Howard RA, Michael P. Klueh MP, et al. The impact of education and prescribing guidelines on opioid prescribing for breast and melanoma procedures. Ann Surg Oncol. https://doi.org/ 10.1245/s10434-018-6772-3. 